NASA/TM-2000-209935

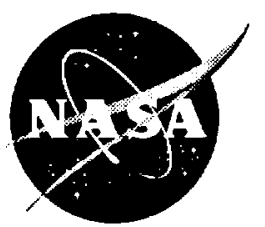

\title{
A New Apparatus to Evaluate Lubricants for Space Applications-The Spiral Orbit Tribometer (SOT)
}

William R. Jones, Jr. and Stephen V. Pepper

Glenn Research Center, Cleveland, Ohio

Mark J. Jansen and QuynhGiao N. Nguyen

AYT Corporation, Brook Park, Ohio

Edward P. Kingsbury

IRC, Walpole, Massachusetts

Stuart H. Loewenthal

Lockheed Martin Missiles and Space, Sunnyvale, California

Roamer E. Predmore

Goddard Space Flight Center, Greenbelt, Maryland 
Since its founding, NASA has been dedicated to the advancement of aeronautics and space science. The NASA Scientific and Technical Information (STI) Program Office plays a key part in helping NASA maintain this important role.

The NASA STI Program Office is operated by Langley Research Center, the Lead Center for NASA's scientific and technical information. The NASA STI Program Office provides access to the NASA STI Database, the largest collection of aeronautical and space science STI in the world. The Program Office is also NASA's institutional mechanism for disseminating the results of its research and development activities. These results are published by NASA in the NASA STI Report Series, which includes the following report types:

- TECHNICAL PUBLICATION. Reports of completed research or a major significant phase of research that present the results of NASA programs and include extensive data or theoretical analysis. Includes compilations of significant scientific and technical data and information deemed to be of continuing reference value. NASA's counterpart of peerreviewed formal professional papers but has less stringent limitations on manuscript length and extent of graphic presentations.

- TECHNICAL MEMORANDUM. Scientific and technical findings that are preliminary or of specialized interest, e.g., quick release reports, working papers, and bibliographies that contain minimal annotation. Does not contain extensive analysis.

- CONTRACTOR REPORT. Scientific and technical findings by NASA-sponsored contractors and grantees.
- CONFERENCE PUBLICATION. Collected papers from scientific and technical conferences, symposia, seminars, or other meetings sponsored or cosponsored by NASA.

- SPECIAL PUBLICATION. Scientific, technical, or historical information from NASA programs, projects, and missions, often concerned with subjects having substantial public interest.

- TECHNICAL TRANSLATION. Englishlanguage translations of foreign scientific and technical material pertinent to NASA's mission.

Specialized services that complement the STI Program Office's diverse offerings include creating custom thesauri, building customized data bases, organizing and publishing research results ... even providing videos.

For more information about the NASA STI Program Office, see the following:

- Access the NASA STI Program Home Page at http://www.sti.nasa.gov

- E-mail your question via the Internet to help@sti.nasa.gov

- Fax your question to the NASA Access Help Desk at (301) 621-0134

- Telephone the NASA Access Help Desk at (301) 621-0390

- Write to:

NASA Access Help Desk

NASA Center for AeroSpace Information 7121 Standard Drive

Hanover, MD 21076 
NASA/TM-2000-209935

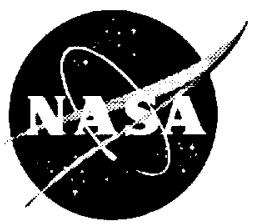

\section{A New Apparatus to Evaluate Lubricants for Space Applications-The Spiral Orbit Tribometer (SOT)}

William R. Jones, Jr. and Stephen V. Pepper

Glenn Research Center, Cleveland, Ohio

Mark J. Jansen and QuynhGiao N. Nguyen

AYT Corporation, Brook Park, Ohio

Edward P. Kingsbury

IRC, Walpole, Massachusetts

Stuart $\mathrm{H}$. Loewenthal

Lockheed Martin Missiles and Space, Sunnyvale, California

Roamer E. Predmore

Goddard Space Flight Center, Greenbelt, Maryland

Prepared for the

2000 Spring Fuels and Lubricants Meeting and Exposition

cosponsored by the Coordinating European Council and Society of Automotive Engineers Paris, France, June 19-22, 2000

National Aeronautics and

Space Administration

Glenn Research Center 
Trade names or manufacturers' names are used in this report for identification only. This usage does not constitute an official endorsement, either expressed or implied, by the National Aeronautics and Space Administration.

Available from

NASA Center for Aerospace Information 7121 Standard Drive Hanover, MD 21076

Price Code: A03
National Technical Information Service 5285 Port Royal Road Springfield, VA 22100

Price Code: $\mathrm{A} 03$ 


\title{
A New Apparatus to Evaluate Lubricants for Space Applications- The Spiral Orbit Tribometer (SOT)
}

\author{
William R. Jones, Jr. and Stephen V. Pepper \\ National Aeronautics and Space Administration \\ Glenn Research Center \\ Cleveland, Ohio \\ Mark J. Jansen and QuynhGiao N. Nguyen \\ AYT Corporation \\ Brook Park, Ohio \\ Edward P. Kingsbury \\ IRC \\ Walpole, Massachusetts \\ Stuart H. Loewenthal \\ Lockheed Martin Missiles and Space \\ Sunnyvale, California \\ Roamer E. Predmore \\ National Aeronautics and Space Administration \\ Goddard Space Flight Center \\ Greenbelt, Maryland
}

\begin{abstract}
Lubricants used in space mechanisms must be thoroughly tested prior to their selection for critical applications. Traditionally, two types of tests have been used: accelerated and full-scale. Accelerated tests are rapid, economical, and provide useful information for gross screening of candidate lubricants. Although full-scale tests are more believable, because they mimic actual spacecraft conditions, they are expensive and time consuming. The spiral orbit tribometer compromises between the two extremes. It rapidly determines the rate of tribochemically induced lubricant consumption, which leads to finite test times, under realistic rolling/pivoting conditions that occur in angular contact bearings.
\end{abstract}

\section{INTRODUCTION}

The performance of lubricated space mechanisms is all-important in assuring a successful mission. In many cases, the premature failure of a lubricated component can result in mission failure [1]. Traditionally, lubricants for space mechanisms have been chosen on the basis of space heritage. Early in the space program, this philosophy was successful because mission lifetimes and mechanism duty cycles were minimal. As mission lifetimes were extended, other components, such as electronics, batteries, and computers, failed before lubrication systems [2]. However, in the last decade these ancillary components have been greatly improved and the tribological systems have become the limiting factors in determining spacecraft reliability.

Therefore, the evaluation of the long-term performance of lubricants and lubricated components is a necessity. The most desirable type of evaluation is life testing of actual components or an entire mechanism under conditions that mimic the application. Ideally, these are non-accelerated tests that accumulate several times the number of cycles that will be seen in actual use in space. For limited missions, this is possible. For extended missions, such as weather satellites, surveillance systems, and deep space probes, this is not possible. Lifetimes may be years, representing millions of duty cycles. A full-scale life test may not be completed until long after the spacecraft has been built and launched. This makes the incorporation of new lubricants, lubricant additives, or new tribological components difficult. 
Traditionally, new tribological materials have been evaluated using conventional test devices such as four-ball, pin-on-disk, Cameron-Plint and others. These tests were developed for terrestrial applications. Therefore, they are usually performed in air and only measure the friction and wear characteristics of the test materials. Obviously for space applications, testing in vacuum is necessary. In addition, most lubricated space components fail, not because of high wear, but due to the consumption of lubricant, which normally can not be replenished.

Recently, a new test device, the spiral orbit tribometer (SOT), was developed by Pepper et al. [3]. It mimics the conditions observed in angular contact ball bearings, a component often used in space mechanisms. This apparatus is a thrust bearing with flat plates for races and a single ball. The test uses only microgram amounts of liquid lubricant on the ball. This small amount of lubricant is consumed by tribochemical action, resulting in short test times. The restriction to small amounts of lubricant is the only "acceleration" method used here. The term "acceleration" refers to the completion of a test in much less time than that required for full scale bearing tests, but still retaining the normal values of operational parameters, such as contact pressure, speed and temperature. This apparatus has been useful in illustrating the importance of surface chemistry in the consumption of a common space lubricant, Brayco 815Z [4]. It has also shown the advantage of using TiC coated bearing balls instead of conventional $440 \mathrm{C}$ stainless steel balls when using Krytox $143 \mathrm{AC}$ as a lubricant [5]. The SOT was used to evaluate various ozonedepleting-chemical (ODC) free cleaning methods compared to a Freon standard [6].

The objective of this work is to fully describe the use of the spiral orbit tribometer for the evaluation of various space lubricants and to compare these results with full-scale bearing life tests.

\section{APPARATUS}

\section{TRIBOMETER}

The spiral orbit tribometer (SOT) appears in Figure 1. It is housed in a stainless steel cube that can be evacuated to a base pressure of less than $1.3 \times 10^{-6} \mathrm{~Pa}$. A cold cathode gauge determines pressure. Alternatively, the system can be operated at atmospheric pressure with gases other than room air. A residual gas analyzer (RGA) with a line of sight to the triboelements determines the composition of gas in the test ambient and also the species evolved from the lubricant during the frictional processes. The RGA and pressure gauge were chosen or modified to eliminate the electrons or ions that they may inject into the test environment.

The tribological elements of the system appear in more detail in Figure 2. Previously introduced by Kingsbury [7], the system is a retainerless steel thrust bearing with a single bearing ball, typically $12.7-\mathrm{mm}(1 / 2$-inch) diameter, placed between two $50.8-\mathrm{mm}$ (2-inch) diameter flat plates. The lower plate is stationary and electrically isolated from ground. Electrical contact resistance is measured from plate to plate through the two lubricated ballplate contacts. The lower assembly is on a shaft supported by a ball bushing and passes through a steel bellows. Load is applied using a deadweight, cantilever system that forces the shaft up, loading the bottom plate and ball against the top plate.

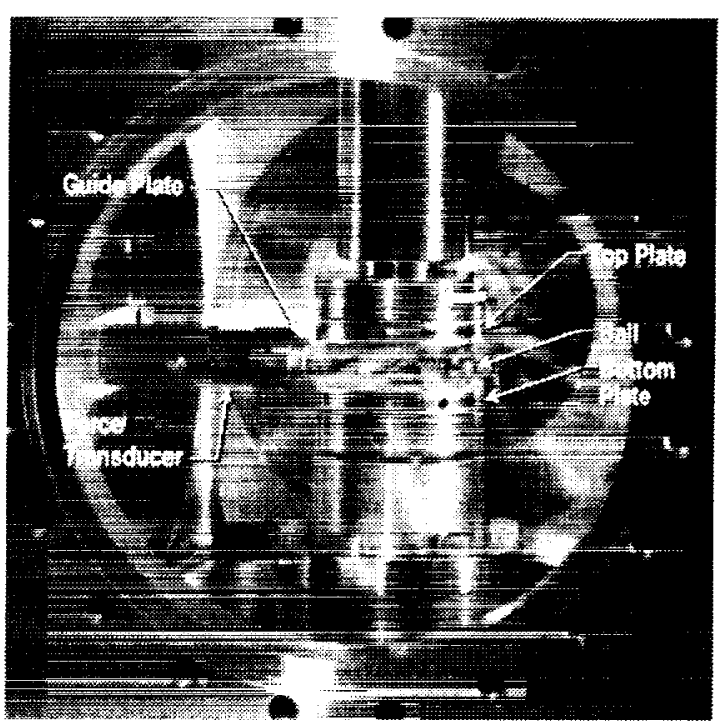

Figure 1 - Vacuum Spiral Orbit Tribometer (SOT)

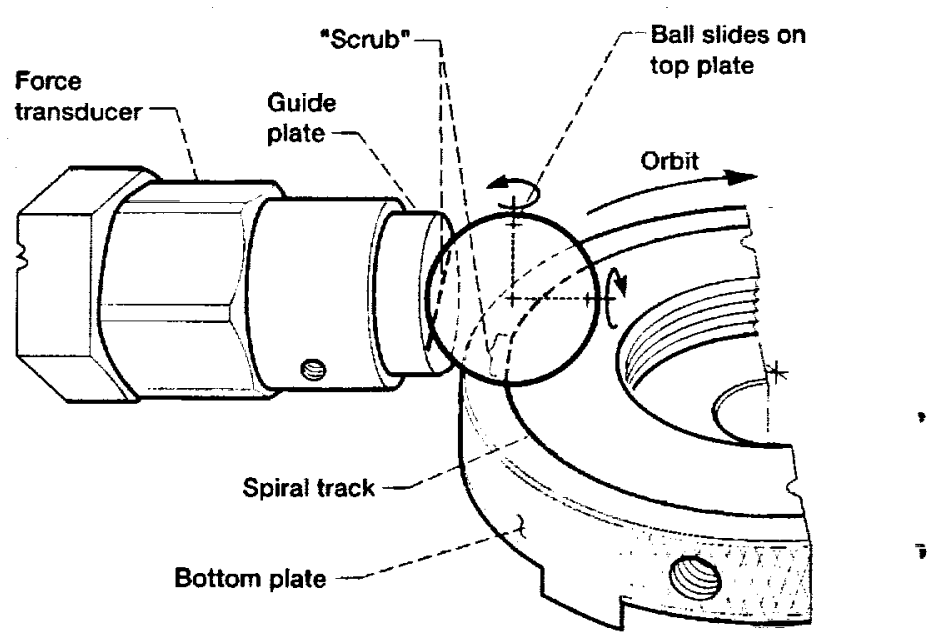

Figure 2 - Detailed view of the SOT components 
The top plate can rotate at speeds up to $\sim 200$ RPM and drives the ball in a spiral orbit ( $\sim 21-\mathrm{mm}$ radius). The rolling ball spirals out from its initial radius toward the edge of the plates with a pitch of approximately $0.5-\mathrm{mm}(0.02-\mathrm{in})$ per revolution. If allowed to continue to spiral without restraint, the ball would eventually fall from between the two plates. However, the ball contacts the vertical guide plate for a short distance (approximately 5-mm (0.2in) every revolution and is forced back into the original orbit radius. The straight-line region where the ball contacts the guide plate is denoted as the "scrub". A transducer in the guide plate mounting arm allows for the measurement of the force required to slide the ball back into its original orbit, thus allowing the coefficient of friction to be calculated. After leaving the scrub, the ball's spiral orbit begins again. The spiral orbit and scrub constitute a track (Figure 2) that is stable, repeatable, and is traversed thousands of times by the ball. A detailed analysis of the ball kinematics appears in Reference 3.

\section{MEASUREMENT AND CONTROLS}

A computer data acquisition (DAQ) and control system developed in Labview ${ }^{\mathrm{TM}}$ operates the tribometer. Analog to digital conversion is done using a 16-bit computer card. The DAQ automatically initiates rotation when the vacuum level reaches $1.3 \times 10^{-6} \mathrm{~Pa}$ and terminates rotation when a preset friction coefficient is exceeded.

\section{PROCEDURE}

\section{MATERIALS}

The ball, guide plate, and two test plates are typically made from hardened AISI $440 \mathrm{C}$ stainless steel, which is a common material for spacecraft bearings. However, any ball or plate material can be substituted, including polymeric or ceramic components. Also, the components can be coated with solid lubricants. Materials tested to date include: $440 \mathrm{C}, \mathrm{M}-50,52100$, and 4150 steels and silicon nitride balls. A variety of solid coatings such as $\mathrm{MoS}_{2}, \mathrm{TiC}, \mathrm{TiCN}$, chromium, aluminum, and gold have also been tested.

\section{PREPARATION FOR LIQUID LUBRICANTS}

First, the plates are polished to a $R_{a}$ of 0.05 microns (2- $\mu$ in) using an aqueous slurry of levigated alumina polishing compound. Next, the specimens are ultrasonically rinsed in deionized water and dried in a stream of nitrogen. All specimens are then cleaned with a solvent/UV-ozone cleaning method detailed in
Reference 6. The ball is lubricated with approximately 50 to 100 micrograms. This is done by placing droplets of lubricant dissolved in an appropriate solvent onto the rotating ball held in a magnetic chuck. As the solvent evaporates, a lubricant film is deposited. The exact lubricant charge is determined by weighing the ball before and after deposition with a sensitive balance. The plates are installed unlubricated.

\section{PREPARATION FOR SOLID LUBRICANTS}

For a solid lubricated system, some or all of the tribological components can be lubricated. Before being coated, the plates are polished in the same fashion as for liquid lubricants. Balls are coated as received or purchased already coated. Post-coating cleaning depends upon the material. In the case of hard or non-reactive coatings ( $\mathrm{TiC}, \mathrm{TiCN}$, etc.), the solvent/UV-ozone method is used before testing. On the other hand, softer coatings ( $\mathrm{Al}$, Au)or coatings that may react to solvents $\left(\mathrm{MoS}_{2}\right)$ are normally tested as received.

\section{PROCEDURE}

The plates are installed in the tribometer, the ball is placed between the plates, and the system is loaded to the desired stress. The test is started when the chamber pressure reaches $1.3 \times 10^{-6} \mathrm{~Pa}$. When the friction coefficient exceeds the failure criteria, the test is automatically shutdown.

\section{EXAMPLES OF LUBRICANT EVALUATIONS}

\section{EFFECTS OF SURFACE CHEMISTRY}

The SOT has been used to demonstrate the severity of tribochemical attack as a function of bearing material on the lubricant lifetime of Fomblin Z-25, a perfluoropolyether (PFPE) [4]. The materials studied were 4150 steel $(1 \% \mathrm{Cr}), 440 \mathrm{C}$ steel $(18 \% \mathrm{Cr})$, chromium plated steel, and aluminum coated steel. Specimens were subjected to the cleaning described above. In all cases $440 \mathrm{C}$ balls were used with approximately $100 \mu \mathrm{g}$ of lubricant. Test conditions were a 4 RPM top plate speed, a mean Hertzian stress of $1.4 \mathrm{GPa}$, and a base vacuum pressure of $-2.7 \times 10^{-7} \mathrm{~Pa}$. Race-race electrical resistance was obtained intermittently throughout the test with a direct current of 1 milliamp and a maximum potential of a few millivolts.

A typical plot of friction force and chamber pressure appears in Figure 3. Friction force is relatively constant throughout the test until a sudden increase at $\sim 1700$ ball orbits. This represents the end of 
lubricated life due to the consumption of the lubricant by tribochemical attack. The chamber pressure was also relatively constant until the friction increase. At this point, the pressure increased and then decreased to values less than steady state rolling. The pressure rise during rolling is due to lubricant volatilization by tribological/tribochemical attack. The decrease of pressure after the friction increase is an indication that little lubricant remains to be degraded, just as the friction rise itself indicates the absence of lubricant and the end of the life test. Table 1 summarizes the results.

Table 1-Fomblin Z-25 life dependence upon materials [4]

\begin{tabular}{|l|c|c|c|c|}
\hline Material & $\mathbf{4 1 5 0}$ & $\mathbf{4 4 0 C}$ & $\mathbf{C r}$ & $\mathbf{A l}$ \\
\hline Friction Coefficient & 0.10 & 0.11 & 0.12 & 0.13 \\
\hline Lifetime, Ball Orbits & 4000 & 2300 & 1400 & 400 \\
\hline $\begin{array}{l}\text { Pressure Rise } \\
\left(\times 10^{-7} \mathrm{~Pa}\right)\end{array}$ & 0.4 & 0.7 & 1.6 & 6.7 \\
\hline Resistance (Ohms) & .2 & 1 & 2 & 10 \\
\hline
\end{tabular}

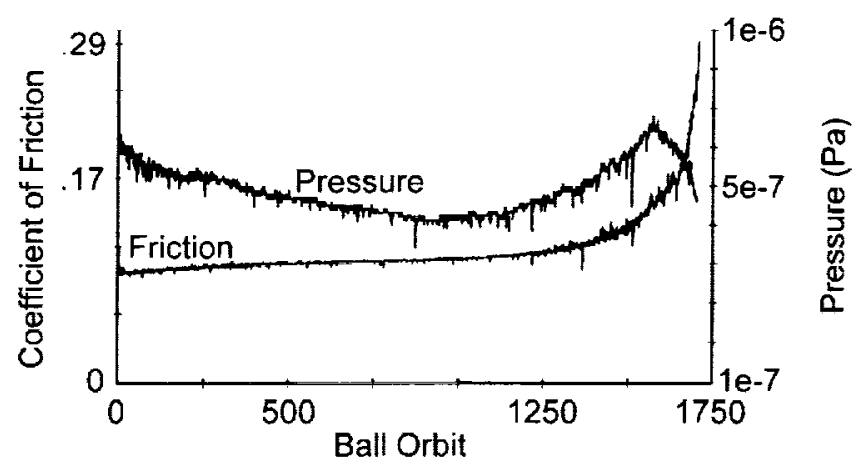

Figure 3 - Friction force and chamber pressure [4]

The focus of interest is the dependence of the tribological parameters on the type of plate material. The 4150 steel plates exhibited an order of magnitude longer lifetime than the aluminum surface. The $440 \mathrm{C}$ and chromium surfaces exhibited intermediate lifetimes. The pressure and resistance data correlate well with the lifetime data and indicate that the 4150 surface is the least aggressive toward Fomblin Z-25 and that the aluminum surface is the most aggressive. The $440 \mathrm{C}$ and chromium surfaces are intermediate. A larger pressure rise correlated with shorter lifetimes, a result expected if the gas evolution is due to lubricant degradation. Also, a high rate of friction polymer formation, indicated by higher electrical resistance across the ball-plate contacts, is expected for higher rates of destruction of the lubricant.
These results clearly demonstrate the effect of increased chromium content on PFPE lubricant degradation rates and is mirrored in the decreased lubricant lifetimes. In addition, the strong catalytic effect of an aluminum surface is also demonstrated.

\section{EFFECT OF HERTZIAN CONTACT STRESS}

The role of Hertzian contact stress on lubricant lifetime of Krytox 143AC, a PFPE, was demonstrated in Reference 5. In these tests, $440 \mathrm{C}$ stainless steel balls were run against $440 \mathrm{C}$ plates at four different mean stress levels $(0.75,1.0,1.5$, and $2.0 \mathrm{GPa}$ ). Other test conditions included $\sim 100 \mathrm{RPM}$, $\sim 50 \mu \mathrm{g}$ of lubricant, and an initial vacuum level less than $1.3 \times 10^{-6} \mathrm{~Pa}$. In addition, a second series of tests were performed under identical conditions, but a TiC coated $440 \mathrm{C}$ ball was substituted for the $440 \mathrm{C}$ ball. These results are summarized in Figure 4.

There is an exponential decrease in lubricant lifetime with increasing stress for both the $440 \mathrm{C}$ and $\mathrm{TiC}$ coated $440 \mathrm{C}$ balls. In addition, substituting a TiC coated ball for the $440 \mathrm{C}$ ball quadrupled lifetime at low stresses and doubled life at higher stresses. The reduced reactivity of the TiC surface with the PFPE lubricant is considered to be the reason for this enhancement. This is another example of the effect of bearing surface chemistry on lubricant consumption rate revealed by the SOT.

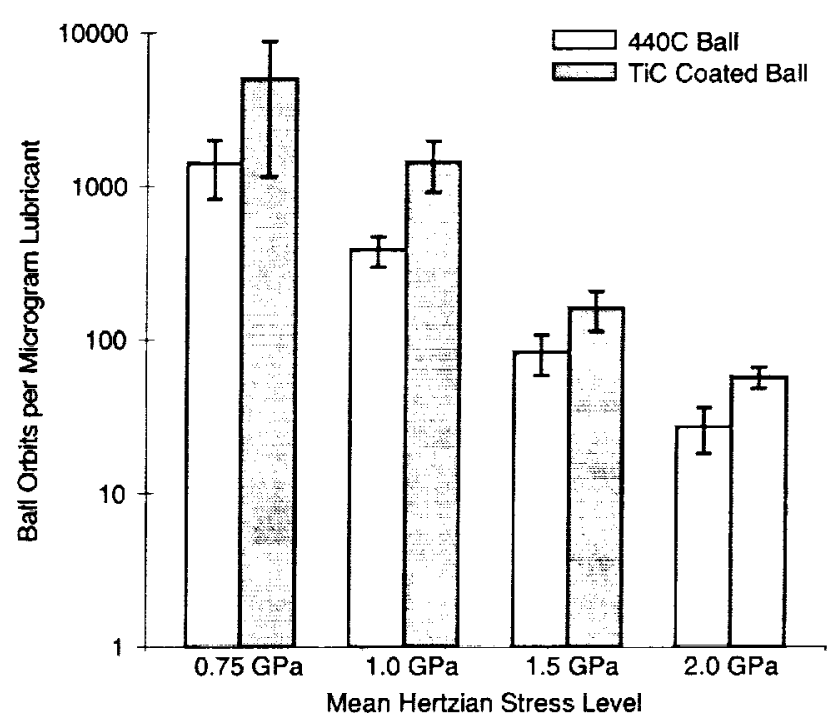

Figure 4 - Effect of stress and $\mathrm{TiC}$ coating on lubricant lifetime (Krytox 143AC) [5] 


\section{EFFECTS OF CLEANING ON LUBRICATED LIFETIME}

The SOT was also used to evaluate the effects of various ozone-depleting-chemical (ODC) free cleaning processes on lubricated lifetime using Fomblin Z-25 [6]. The $440 \mathrm{C}$ parts were cleaned using the following methods: 3 solvent/UV-ozone, aqueous levigated alumina slurry (ALAS), supercritical (SCF) $\mathrm{CO}_{2}$, aqueous Brulin ${ }^{\mathrm{TM}}$ 815GD, and Freon 113 as a baseline. Other test conditions were a mean Hertzian stress of $1.5 \mathrm{GPa}, 10 \mathrm{RPM}$ top plate speed, $\sim 50 \mu \mathrm{g}$ of lubricant, and an initial vacuum of less than $1.3 \times 10^{-6} \mathrm{~Pa}$. The results are summarized in Figure 5. Results showed that none of the cleaning methods had a detrimental effect on lifetime. They also agree with preliminary results from full-scale life tests being performed at Lockheed Martin $[8,9]$.

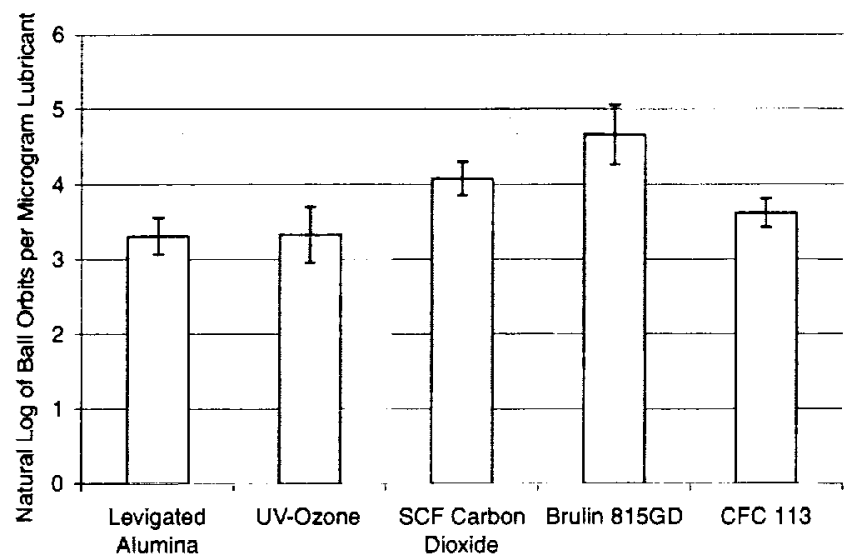

Figure 5 - Effect of ODC-free cleaning techniques on lubricated lifetimes (SOT, $10 \mathrm{RPM}$, room temperature, linear PFPE $(Z-25))[6]$

\section{CORRELATION WITH ENERGY DISSIPATION CALCULATIONS}

Energy is dissipated in a rolling element bearing as a result of pivoting in the Hertzian contact region. This same process is duplicated in the SOT during the rolling portion of the orbit and in the scrub, when the ball experiences a pure sliding contact at the upper plate. This energy dissipation is the driving force for lubricant degradation. A detailed analysis of energy loss during rolling/sliding in a 3-ball system appears in Reference 7. The same analysis can also be applied to one ball operation. The total energy dissipation per unit time is termed "severity". The severity can be integrated over the time of a complete orbit. Assuming that lubricant lifetime is inversely proportional to the energy dissipated during an orbit, relative lifetimes at different stresses can be calculated. These data, plotted as a function of load, appear in Figure 6. All lifetime data is normalized to the highest load. Experimental data for relative lifetimes for both $440 \mathrm{C}$ and TiC coated $440 \mathrm{C}$ appear as well. There is good agreement between the calculated and experimental results. Thus, the stress dependence on lubricant lifetime may be understood on the basis of lubricant degradation by friction energy dissipation at the ball/plate contact.

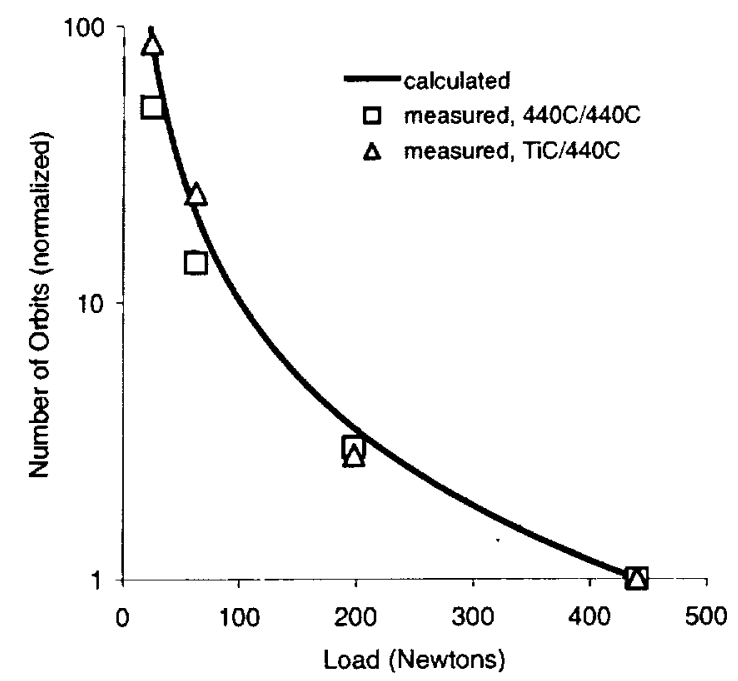

Figure 6 - Severity calculation for SOT and comparison to stress level tests with Krytox 143AC [5]

\section{CORRELATION WITH FULL-SCALE VACUUM BEARING TESTS}

One of the goals of accelerated tribological tests such as the SOT is to include the ability to predict relative lifetimes for different lubricants, conditions, and material combinations for actual space bearings. Unfortunately, little data exists for full-scale bearings because of the time and cost required to run these tests. However, one study with actual spacequalified bearings has been reported which included two common space lubricants, Pennzane 2001 and Braycote $815 Z$. Bearings retainers and balls were made from $440 \mathrm{C}$ and TEFLON'M toroids were used. Both of these lubricants have been studied in the SOT at $1.5 \mathrm{GPa}$ and their normalized lifetime results appear in Figure 7. Based on these results, a 40-fold increase in bearing lifetime for Pennzane compared to Brayco $815 Z$ is predicted. Freon cleaned bearing results from Loewenthal et al. [8] are shown in Figure 8. Although four different cleaning procedures were used in this study and one Pennzane test is still running, the average lifetime improvement is greater than 10 times. This is a good correlation and demonstrates the ability of the SOT to predict practical results. 


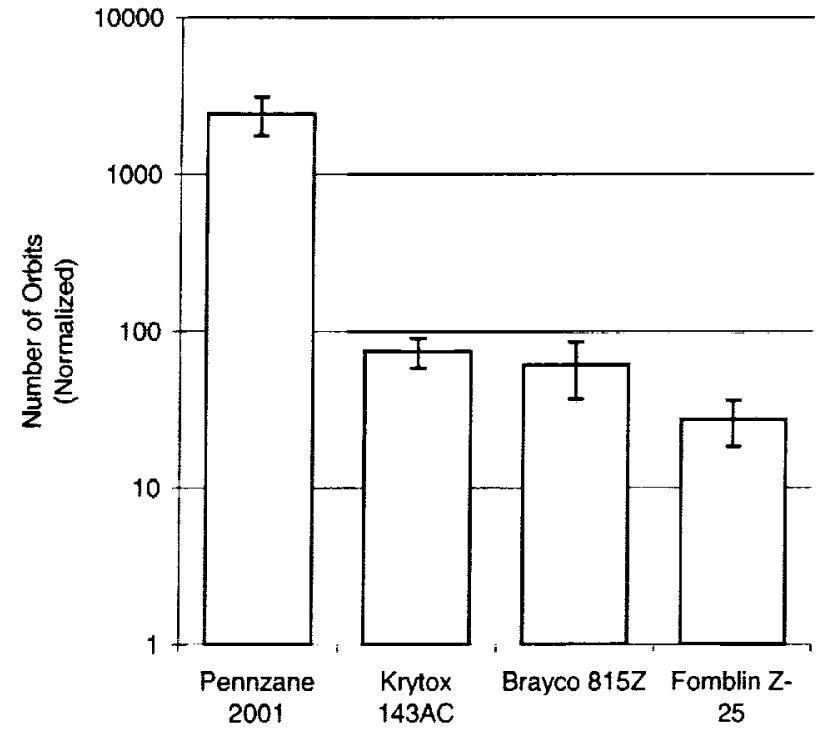

Figure 7 - Relative lifetimes of various space lubricants using the SOT

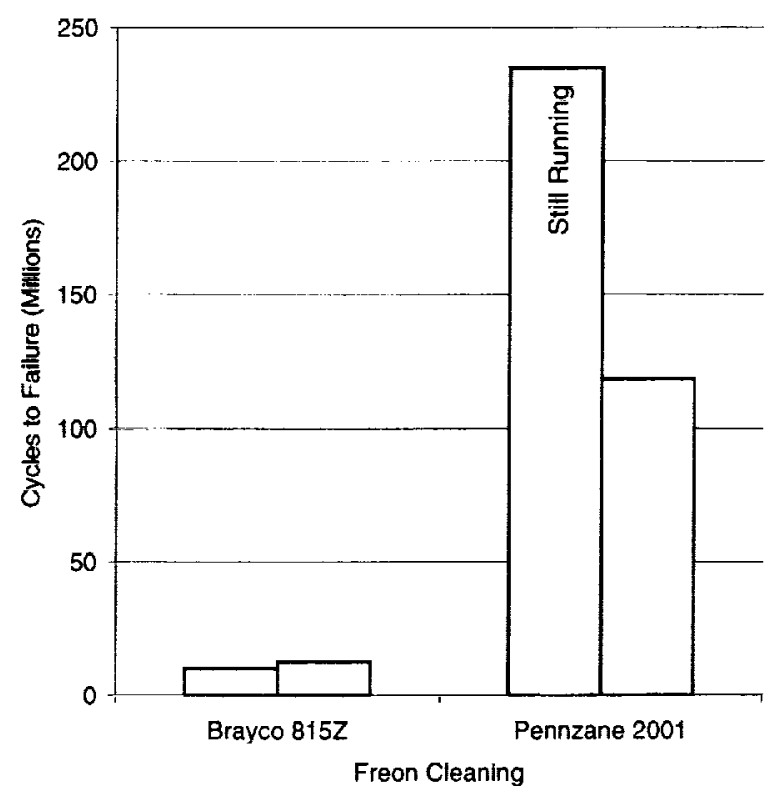

Figure 8 - Life data from Lockheed Martin bearing test [8]

\section{EFFECT OF TEST ENVIRONMENT}

Although the SOT was originally designed to operate in ultrahigh vacuum, it may also be used at atmospheric pressure with different gases. For example, $\mathrm{MoS}_{2}$, a solid lubricant commonly used in space applications $[10,11]$, has been tested in two different environments - dry air and room air $(50 \%$ $\mathrm{RH})$. It is well known that the friction of $\mathrm{MoS}_{2}$ is higher in humid air than in dry air or nitrogen. This behavior is demonstrated by the SOT in Figure 9. Here, the friction coefficient as a function of test time and test atmosphere is shown. In dry air, a low friction coefficient is observed, but when the atmosphere is change to humid room air, the friction immediately increases, as expected. The friction returns to its low value as soon as the humidity is removed.

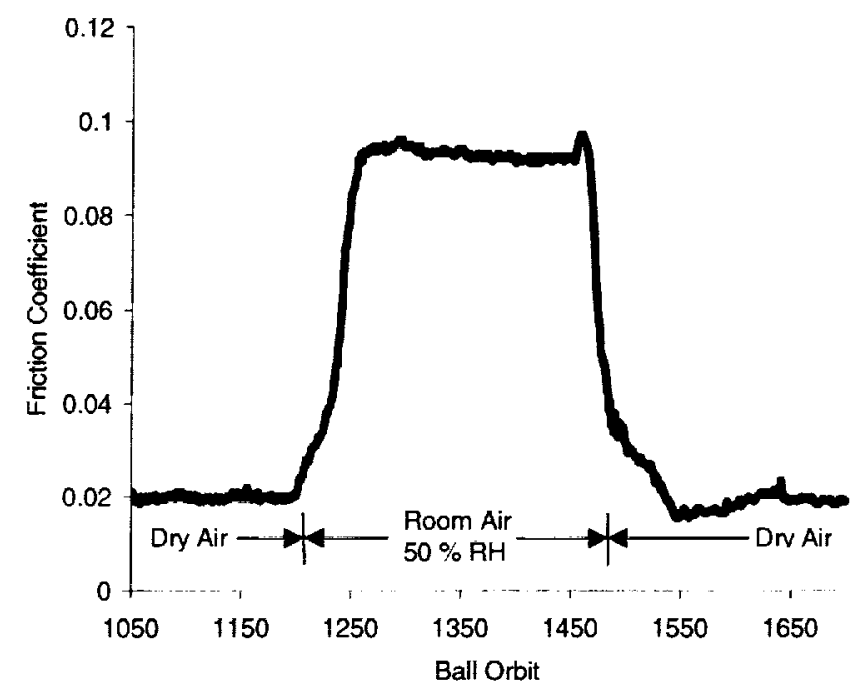

Figure 9 - The effect of humidity on the friction of a $\mathrm{MOS}_{2}$ lubricated ball in the SOT

\section{CONCLUSION}

A new instrument for accelerated testing of vacuum bearing lubricants, the spiral orbit tribometer (SOT), has been described. Examples of how this instrument can rapidly reveal the effects of varying contact stress or bearing surface chemistry on lubricant lifetime have been illustrated. In addition, the effect of test atmosphere on the friction coefficient is shown. Correlation between full-scale vacuum bearing life tests is reported.

\section{CONTACT}

For further information or questions about the SOT, contact Stephen Pepper at NASA Glenn Research center.

Phone: (216) 433-6061

Email: Stephen.V.Pepper@grc.nasa.gov 


\section{REFERENCES}

1. Jones, W.R., Jr., Jansen, M.J., "Space Tribology", NASATM-2000-209924, April 2000.

2. Fleishauer, P.D., Hilton, M.R., "Assessment of the Tribological Requirements of Advanced Spacecraft Mechanisms", Aerospace Corp, El Segundo, CA, Report No. TOF0090 (564)-1, 1991.

3. Pepper, S.V., Kingsbury, E., Ebihara, B.T., "A Rolling Element Tribometer for the Study of Liquid Lubricants in Vacuum", NASA TP 3629, October 1996.

4. Pepper, S.V., and Kingsbury, E., "Destruction of Fomblin Z-25 by Different Bearing Metals", Proc. Inter. Rolling Element Bearing Symp., REBG, Orlando, FL, April 28-30, 1997.

5. Jones, W.R., Jr., Jansen, M.J., Helmick, L.H., Nguyen, Q.N., Wheeler, D.W., Boving, H.J., "The Effect of Stress and TiC Coated Balls on Lubricant Lifetimes using a Vacuum Ball-on-Plate Rolling Contact Tribometer", NASA TM-1999-209055, March 1999.

6. Jansen, M.J., Jones, W.R., Jr., Wheeler, D.W., "Evaluation of Non-Ozone-Depleting-Chemical Cleaning Methods for Space Mechanisms Using a Vacuum Spiral Orbit Rolling Contact Tribometer", NASA TM to be published, April 2000.
7. Kingsbury, E., "Tribology in Slow Rolling Bearings", Mater. Res. Soc. Sym. Proc., 140, 437-442, 1989.

8. Loewenthal, S.H., Jones, W.R., Jr., and Predmore, R.E., "Life of Pennzane and $815 Z$ Lubricated Instrument Bearings Cleaned with Non-CFC Solvents", NASATM-1999-209392, September 1999.

9. Loewenthal, S.H., Jones, W.R., Jr., Grout, J., Predmore, R., Thom, R., "Instrument Bearing Life with Non-CFC Cleaners", Proc. Inter. Rolling Element Bearing Symp., REBG, Orlando, FL, April 28-30, 1997.

10. Lince, J.R., Fleishauer, P.D., "Solid Lubricants", Chapter 7 in Space Vehicle Mechanisms: Elements of Successful Design, (P.L. Conley, editor), John Wiley \& Sons, Inc., New York, 153-183, 1998.

11. Loewenthal, S.H., Chou, R.G., Hopple, G.B., Wenger, W.L., "Evaluation of Ion-Sputtered Molybdenum Disulfide Bearings for Spacecraft Gimbals", Trib. Trans., 37, 1993. 


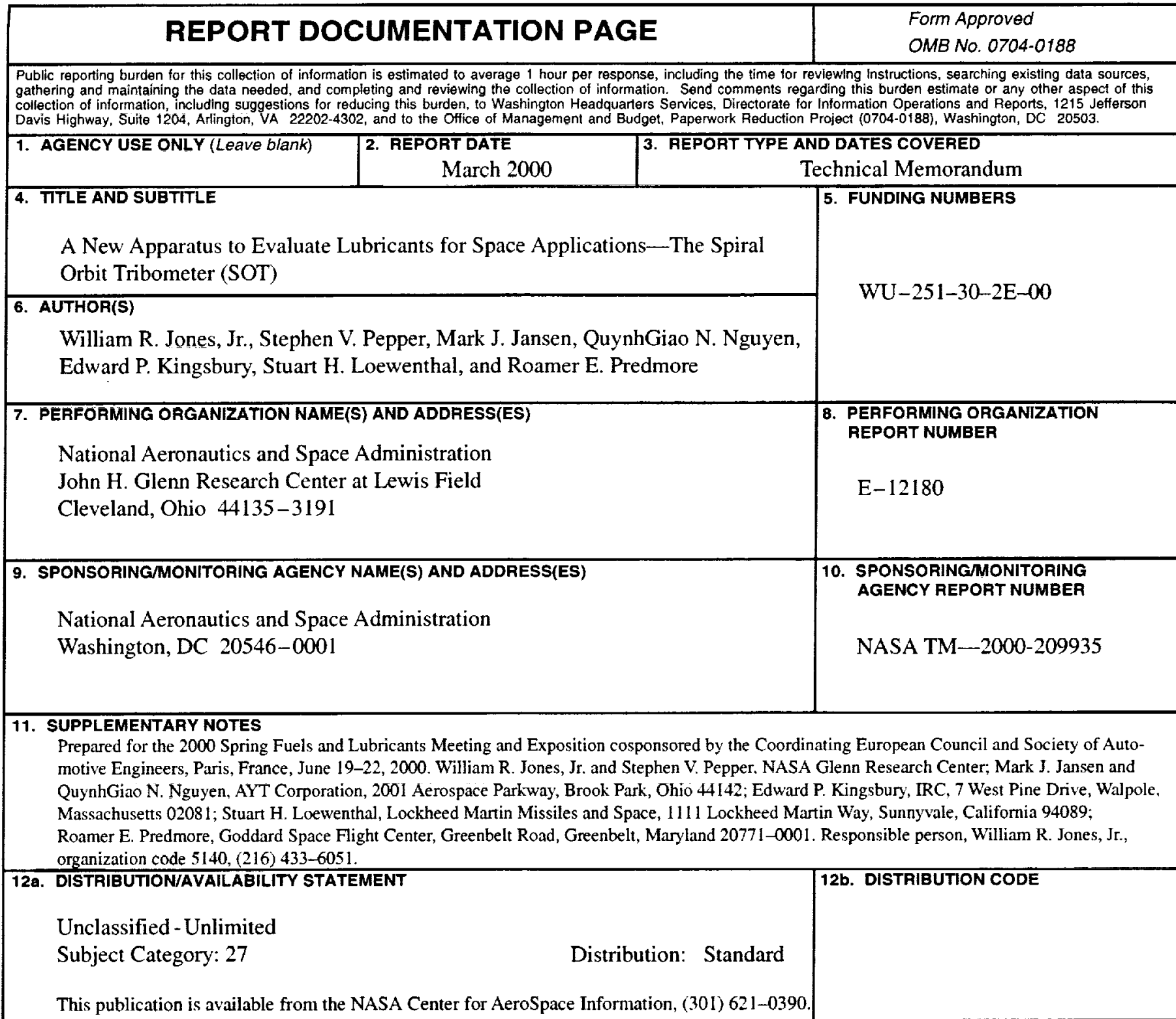

13. ABSTRACT (Maximum 200 words)

Lubricants used in space mechanisms must be thoroughly tested prior to their selection for critical applications. Traditionally, two types of tests have been used: accelerated and full scale. Accelerated tests are rapid, economical, and provide useful information for gross screening of candidate lubricants. Although full-scale tests are more believable because they mimic actual spacecraft conditions, they are expensive and time consuming. The spiral orbit tribometer compromises between the two extremes. It rapidly determines the rate of tribochemically induced lubricant consumption, which leads to finite test times, under realistic rolling/pivoting conditions that occur in angular contact bearings.

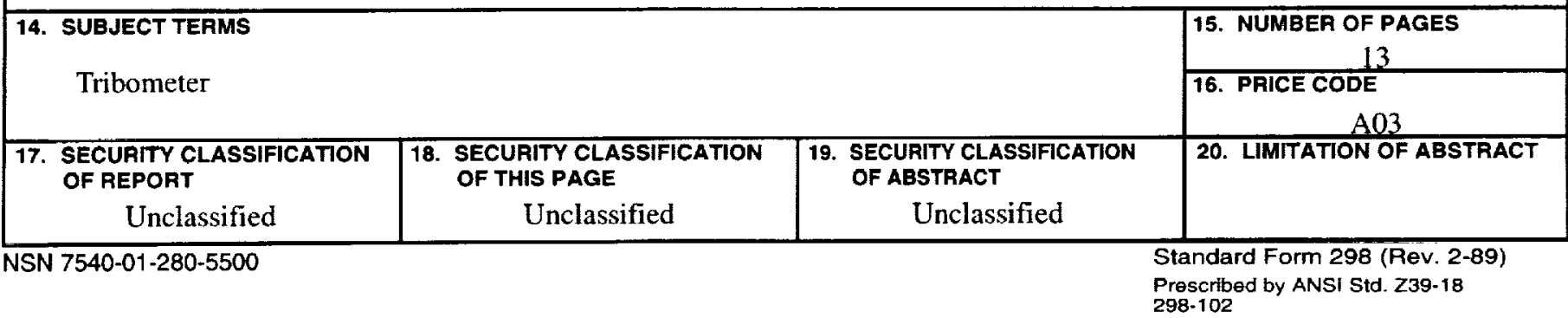

